\title{
Professional Development and the Informal Curriculum in End-of-Life Care
}

\author{
Megan Baker • Judith Wrubel • Michael W. Rabow
}

Published online: 25 February 2011

(C) The Author(s) 2011. This article is published with open access at Springerlink.com

\begin{abstract}
Although professionalism has emerged as a key competency for today's physicians, there exists little insight into how best to teach medical students the relevant skills or instill in them the commitment required to practice according to the highest professional standards. Ten UCSF medical students were interviewed at three time points (second, third, and fourth years of school). Interviews focused on students' learning and development regarding end-of-life care (EOLC). Students described varying steps in their professional development from their second to fourth years of school, including feeling confused about the definition of professionalism and integrating their personal and professional identities. In addition to professional development, four other themes contributed to the development of medical student understanding of how to provide EOLC as a professional: (1) curricular discordance, (2) role models, (3) the tightrope between trained versus human reactions, and (4) ethical dilemmas. These five themes represent dilemmas that students often learned how to
\end{abstract}

M. Baker $(\square)$

School of Medicine, University of California, San Francisco,

301 Parnassus Ave, \#305,

San Francisco, CA 94117, USA

e-mail: megan.baker@ucsf.edu

J. Wrubel

Osher Center for Integrative Medicine, University of California,

San Francisco,

3333 California Street,

San Francisco, CA 94143, USA

M. W. Rabow

Division of General Internal Medicine, University of California,

San Francisco,

1701 Divisadero Street,

San Francisco, CA 94143, USA respond to over the course of school. Professional development in EOLC required the acquisition of skills necessary to balance the tension between and navigate conflicting messages present in medical student training.

Keywords Professionalism - Medical practice - End-of-life care $\cdot$ Professional development

\section{Introduction}

Educators, major medical organizations, and the public recognize that a key element of medical education is the development of professionalism - a combination of skills (technical and cognitive) and character (respect for patients, humanism, and compassion) [1-4]. How professionalism is best taught, promoted, and supported is currently debated [5-8]. Ethical and compassionate care by physicians is key to providing quality end-of-life care (EOLC), but relatively, little is known about medical student professional development in EOLC, and there is evidence that this training process is inadequate [9]. Student training is the result of both formal (lectures and official pronouncements) and informal (social milieu, interpersonal relationships, and unofficial messages) curricula [10]. Prior retrospective and cross-sectional observations about EOLC training suggest that medical students have poor role modeling and supervision, and even suffer ethical erosion [11-14]. Studying EOLC education in more detail and over time is necessary to understand the changes and growth that constitute the process of professional development in EOLC. Using a unique longitudinal, qualitative dataset, we sought to document the process of professional development training in EOLC during medical school. 


\section{Methods}

We conducted a qualitative analysis of student narratives about EOLC training over the final 3 years of medical school. The interviews were part of the Hidden EOLC Curriculum Study, a mixed-method exploration of the informal curriculum in EOLC medical education [13]. In 2005, 141 University of California, San Francisco (UCSF) second year medical students $(86.5 \%)$ completed surveys about their EOLC experiences. Ninety-one (64.5\%) were willing to be interviewed. Ten of these were chosen randomly and consented to be interviewed. The study received Institutional Review Board approval prior to data collection.

The data set consists of 30 transcripts of one-on-one semistructured interviews conducted by one author (MR) annually during the students' second through fourth year. The interview protocol included open-ended questions with follow-up probes concerning the students' perception of the EOLC education, their observations about physician reactions to dying patients, and their own EOLC experiences (Appendix).

The audio-recorded narratives were transcribed and assigned confidential identifiers for analysis. Using a teambased method of qualitative analysis [14], two experienced researchers (MR and JW) individually read and provisionally analyzed the narratives and then together identified recurrent themes $[15,16]$. Beginning with three randomly selected interviews and guided by interview content focused on experiences of meaning for the student, the researchers developed a coding protocol, adding and refining codes as they appeared in each subsequent interview, until achieving saturation. All interviews were coded independently by both coders who met to verify the codes. Coders achieved immediate concordance on approximately $90 \%$ of codes. Disagreements were resolved through discussion.

Coded cases were entered into ATLAS.tiC, a software program for the management of narrative data. A third researcher $(\mathrm{MB})$ reviewed the transcripts and codes in preparation for the analysis and found no additional themes or miscoded text. Frequencies and descriptive statistics were calculated for the demographic data using SPSS $\odot$ software.

\section{Results}

The ten students had a mean age of 25.2 years during the first interview; six were female. Each of the students completed the interview annually for 3 years. Analysis identified five central themes (Table 1): (1) professional

Table 1 Definitions and instances of codes used in analysis

\begin{tabular}{|c|c|c|c|}
\hline Code & Definition & Example & $\begin{array}{l}\text { Number of times the } \\
\text { code was identified } \\
\text { in the } 30 \text { transcripts }\end{array}$ \\
\hline $\begin{array}{l}\text { Professional } \\
\text { development }\end{array}$ & $\begin{array}{l}\text { The process of how medical students and } \\
\text { physicians learn to care for patients at the EOL } \\
\text { and develop their professional values and } \\
\text { attitudes. }\end{array}$ & $\begin{array}{l}\text { "Because every single doctor you talk to gives } \\
\text { you a different idea of what professionalism is } \\
\text { about and so you're sort of left struggling to } \\
\text { find your version." }\end{array}$ & 41 \\
\hline $\begin{array}{l}\text { Curricular } \\
\text { discordance }\end{array}$ & $\begin{array}{l}\text { Conflicting messages communicated by the } \\
\text { formal and informal curricula regarding the } \\
\text { proper way to address EOLC. }\end{array}$ & $\begin{array}{l}\text { "I think that's true, lecture tends to be a lot more } \\
\text { idealistic and clinical experience is more what } \\
\text { the real world is about." }\end{array}$ & 115 \\
\hline Role models & $\begin{array}{l}\text { Examples set for handling EOLC issues by } \\
\text { supervisors and those further along in their } \\
\text { training. }\end{array}$ & $\begin{array}{l}\text { "The interns are so busy that they're totally into } \\
\text { getting things done so they couldn't be very } \\
\text { good role models for me." }\end{array}$ & 88 \\
\hline Tightrope & $\begin{array}{l}\text { Disconnect between how physicians and } \\
\text { nonprofessionals react to medical situations; what } \\
\text { is deemed professional at times conflicts with a } \\
\text { natural human response to EOL. }\end{array}$ & $\begin{array}{l}\text { "You actually have to step outside in order to be } \\
\text { human but in it you have to be professional, } \\
\text { which means dispassionate and competent... } \\
\text { cordial of course, but you don't get into the real } \\
\text { stuff of life, that stays on hold once you put on } \\
\text { your jacket." }\end{array}$ & 43 \\
\hline Ethical dilemmas & $\begin{array}{l}\text { An apparent conflict between moral principles } \\
\text { each held to be important in medical practice. }\end{array}$ & $\begin{array}{l}\text { "I mean [the interns] really were primary } \\
\text { caregivers and they were having us do things } \\
\text { that they didn't necessarily think were helpful } \\
\text { in the overall picture, which kind of violates the } \\
\text { 'Do no Harm' part or at least trying to always } \\
\text { do some benefit to what your interventions } \\
\text { are." }\end{array}$ & 71 \\
\hline
\end{tabular}

$E O L$ end-of-life, $E O L C$ end-of-life care 
development, (2) curricular discordance, (3) role models, (4) the tightrope between trained versus human reactions, and (5) ethical dilemmas. Within each theme, students described insights or realizations that helped them navigate conflicting curricular messages.

\section{Professional Development}

Students were confused about what constituted professional behavior. "Because every single doctor you talk to gives you a different idea of what professionalism is about and so you're sort of left struggling to find your version." Students felt some of the professional values they were learning could conflict with previously held values: "As third year medical students, I think our focus on why we even went to medical school can sometimes get lost."

Early students believed that they did not have a strong voice or much influence over the way patients were treated. They did not feel entitled to question their superiors or ask for explanations. "As a third year you don't feel like you really have any power to say, 'Hey can we talk about what's going on here?"”

Second year students reported being warned about the threat of erosion of personal values and becoming less empathetic: "The whole thing about medical school has me worried in terms of becoming 'jaded.' I always hear about the stereotype of the eager medical student who is very nice with patients and the further up you go you become more bitter and callous."

Students talked about the value of experience with EOLC prior to medical school in helping solidify their professional values about EOLC. "Some of the things I came away with from my [prior] experiences are very contrary to what the philosophies here are and I am still trying to sort out what it is I value and what should be valued." Importantly, students reflected that outside experience may actually have complicated their development as a student: "I think I am probably more confused [than other students] because it's definitely less clear cut to me where I see things that I don't agree with and if you've never been exposed to something else, how would you know there's a different way of handling it?"

Ultimately, fourth year students learned how to function or how to accept how they functioned within the system. "In a lot of ways there's some disillusionment in medicine when you get in and things aren't the way you wanted to practice. I mean I think I'm going to do my best, that's all I can do. There's no way to make an ultra structural change to the pattern."

\section{Curricular Discordance}

Students learned the conduct of a medical professional through formal and informal curricula, and curricular messages were at times conflicting. In some instances, the informal curriculum taught that the role of a physician-intraining does not include addressing EOLC. "I felt the team was like, 'We're just getting rid of him kind of thing; we don't really need to go in there." Other times, the informal curriculum validated physicians' roles in EOLC. "We had patients die and our attending was very caring with the patients, felt very bad when patients died and tried his best to make the patients as comfortable as possible, even if the patient was unconscious."

Similarly, students experienced varied informal curricular messages with respect to emotional reactions to EOLC. Some felt pressure to conceal emotions, "I am feeling overall in medicine that there is pressure to bottle up emotions and be very business-like in our practice." Others were encouraged to express emotion: "We did a formal med student teaching session, where we talked about really emotional experiences. And a very supportive thing where the attending who was teaching it brought in poems on the subject..."

Fourth year students learned to assess the relative value of conflicting curricular messages: "I didn't think that the surgical approach to end-of-life care was what I thought it could be based on what we learned in class..." One student specifically discussed a possible explanation or justification for the discrepancies between the formal and informal curriculum, noting a difference between people and the institution in which they work. "I don't think when we hire clinicians that we interview people based on their values of end-of-life care. It doesn't mean that [the medical center] as a whole doesn't value end-of-life care but if somebody has an individual experience with one of those people, they may generalize to the rest."

\section{Role Models}

Students recounted experiences with role models at length, including superiors who handled EOLC situations in a helpful way (positive), who set an example that students did not want to follow (negative), or who seemed unavailable to instruct on EOLC issues (absent). Positive role models included attendings and residents who cared, took time to address dying patients' needs, and who reflected on their own reactions to patients who died. "[Some attendings] still have that fire and that light in their eyes and their interactions with patients are amazing." Positive role models provided literature and dedicated poems to patients and invited team members to share their feelings about patients and EOLC. Positive role models provided examples of how to deal with medicine's emotional demands. Reflecting on an attending who openly discussed being sad, one student said, "I think it was helpful to remember that everybody was human. I guess feeling like it could be a safe thing to do both for us and for [patients]."

In contrast, negative role models appeared insensitive to end-of-life issues. "My preceptor was very competent and very good, but not the most compassionate. Sometimes I could 
see her getting mad at her patients who were dying and not really understanding what was happening for them emotionally, and what it felt like to know that you were dying."

Absent role models represented a missed opportunity to educate students about EOLC. Typically, absent role modeling involved not addressing the death of a patient. "She came in and her patient was not there and she said, 'Where is Miss So and So?' And they were like, 'Oh she died.' There was no discussion about what had gone on."

Discerning between positive and negative role modeling allowed students to learn from both. "At the end of my third year, I remember very vividly seeing a couple of residents and one attending, who I thought highly of in many other respects, give a very bad 'bad news' conversation. And I remember thinking, 'Wow I can learn so much from this person but I'm actually learning something from somebody doing something differently than I had been taught to do it." Another method of reconciliation was to consider bad role models as good doctors operating within a dysfunctional system: "Depending on the situation if it was kind of a crazy situation in terms of someone dealing with a lot of patients, a lot of sick patients, and not having time to sort of do what you would expect to have been done, then I talked about the system's kind of problems."

\section{The Tightrope Between Trained Versus Human Reactions}

The tightrope is a metaphor for the demand to manage the conflict between students' perception of how medical professionals deal with EOLC and what felt natural or human in dealing with their own and their patients' reactions. Students reported pressure to conform to expectations that were sometimes at odds with their perception of what was right from a humanistic perspective. "You actually have to step outside in order to be human but in it you have to be professional, which means dispassionate and competent... cordial of course, but you don't get into the real stuff of life, that stays on hold once you put on your jacket."

Despite their own powerful emotional experiences, many students received the message that the competent professional remains distant emotionally ("One of the first few things that I learned early during medical school is that you don't get involved with or develop a relationship with your patients.") or, at the very least, hides human emotions ("I think a lot of people here are very good at showing a front where they are together. You kind of have to do that in medicine, just to function, where you can't let whatever might be bothering you show or affect your work.").

As students progressed through school, they became aware of the conflict between a trained and human approach to end-of-life and made a conscious effort to manage the conflict. One fourth year student concluded: "It is possible to balance the two. And it's through examples that I've come to that conclusion, great clinicians that have been able to do both."

Another fourth year student utilized the concept of selfreflection and self-regulation in learning to walk the tightrope, "At least I'm a little more sensitized to notice when I'm getting off track to where I want to be and hopefully as the pressure comes on and I kind of start to veer off track during internship, which I'm sure will happen, I'll hopefully be sensitive enough to get myself back."

\section{Ethical Dilemmas}

Students described the complexity of balancing competing ethical principles of nonmaleficence, beneficence, and autonomy. They also spoke of student-specific dilemmas such as balancing clinical care with learning. In many instances, potential solutions were not discussed explicitly; rather, students were left to observe their supervisors' behavior and make their own conclusions about the relative value of the ethical principles. "I remember the residents saying, 'We should just send her home because I think she wants to die at home.' And she ended up dying in the hospital and I don't know why the decision was made to keep her in the hospital. I don't know if it was formally discussed."

Some students demonstrated the ability to take an overt, personal stand around ethical issues, which is notable because this action subverts the medical education hierarchy. "[An attending] wanted us to do a procedure that we were not trained in on a patient in ICU who was probably dying. I didn't feel comfortable doing it, so I said no thank you, because I hadn't seen it done and hadn't heard the instructions yet." However, by fourth year, not all students developed this ability to insist on the right care for their patients. "I thought that the ethics committee should have been involved in her case, but I never said that."

Fourth year students recognized that medical decisions often involved conflicting ethical principles and sometimes with no right outcome: "There was really no good answer; a young woman with a lot of comorbidities and just very poor capacity to make her own decisions with nobody else in the world to help."

\section{Conclusion}

In these interviews, second and third year medical students discussed prior experiences with EOLC, warnings of acculturation, confusion about the meaning of "professional," and agreed they lacked a voice within their ward teams. Students received contradictory messages where professional behavior felt at odds with human reactions. Students similarly described inconsistent teachings in the formal and informal EOLC curricula and variable examples set by role 
models. Students describe a wide variety of ethical dilemmas with conflicting values and at times no clear solutions. Fourth year students tended to demonstrate integration of their personal values and the perceived values of the medical system. By the fourth year, many students came to accept curricular conflicts as inevitable while developing an ability to discern what they felt was right amidst the confusing set of messages received.

Limitations of this study include a small sample size from a single institution. Interviews were open-ended and time-limited, and not all students addressed each theme during their interview. Analysis is able only to provide a description of student's responses, and no objective data are available to compare students' experiences with their actual educational exposures.

Given these limitations, our findings are consistent with prior observations that students face differing expectations about how physicians handle emotions [14], conflicting curricular messages [12], inconsistent quality of role models [9], and ethical dilemmas [11] as part of their training. Further, our data deepen this understanding by offering a unique longitudinal perspective, following a set of individual students as they progress from passive observers to more critical consumers of their EOLC experiences. Students developed skills of discernment in each of these areas that contributed to their determination of appropriate professional practice. Observing prospectively over time, however, ethical erosion was not found among these students.

Professional development can be seen as the acquisition of the ability to reconcile the conflicts inherent in medical education. Our data supported previous findings that "negotiation of these conflicts" develops professional character [17]. Professional development includes learning the skill of discernment within a number of basic conflicts in medical education: (1) the informal versus formal curriculum, (2) positive versus negative role models, (3) the tightrope of professional versus human reactions, and (4) ethical dilemmas. We found many instances of successful professional development. But, observing students who remained confused, conflicted, or unwilling to take a stand, we also found evidence that some students may not get the necessary training and supervision to develop adequately. The process of professional development in EOLC we observed was largely unsupervised and left to chance rather than carefully controlled and directed by well-trained faculty and defined educational processes. Medical students lacked access to a consistent authority on what constitutes appropriate professional behavior.

Our study supports the proposition that successful training in professional development will require reflection and integration of personal and professional identity in a safe community of learners, exercising discernment in the context of competing ideals, positive role modeling, and making implicit instruction explicit and open for critique [18-20]. In the dynamic profession of medicine, students must develop an inner compass in preparation for navigating unforeseeable circumstances. The training necessary for this requires a deep commitment, including supporting faculty as they work to provide the supervision necessary to guide medical students through the complex process of professional formation $[18,21]$.

Open Access This article is distributed under the terms of the Creative Commons Attribution Noncommercial License which permits any noncommercial use, distribution, and reproduction in any medium, provided the original author(s) and source are credited.

\section{Appendix-Interview Protocol}

Preparation

Thank you

Reassure about confidentiality

Confirm demographics

Confirm electives

Introduction

This interview is about the experiences you've had at UCSF with EOLC:

Education in lectures and classes

Experience with patients and preceptors

Messages you've gotten informally

Please think about all your experiences, both formal and informal, that have impacted what you know or how you think about caring for patients who are nearing the end of their lives.

\section{Formal Curriculum Learning}

What have you been taught in medical school so far about taking care of patients at the end of life?

Prompts:

- Breaking bad news

- Advance directives

- Physician responsibility

- What to do with emotions

Where did you learn it? (class, elective, preceptorship)

From whom?

Have you ever taken care of a patient who died?

Please describe the experience.

Was the death talked about? 
What aspects of it (medical details, emotions of patient/ family, emotions of MDs)

By whom?

How? Where?

Did you observe any rituals around care of patients who were dying or died?

\section{Informal Curriculum Learning}

Sometimes, information and attitudes are communicated informally or implicitly rather than directly. For instance, construction of the large Mission Bay campus suggests that biomedical research is highly valued at UCSF. Or, if your resident says that third year students should go home by 5 p.m., but then makes fun of her students for all the sleep they got on call nights, the implicit message (or unwritten rule) might be "Good students stay late."

What underlying messages about caring for people at the EOL have you picked up during medical school thus far?

How was the message delivered?

By whom?

Sometimes, these hidden messages are even discordant with what is being taught officially or formally. For instance, if someone says during a lecture that attention to the psychological aspects of care is important, but spends no other time on it during their lectures, or makes light of it later on, that person doesn't model psychological attention, and you might come away with the message that psychological care really isn't that important.

Were any of the EOLC messages discordant with explicit or official teachings?

Prompts:

Have you heard faculty or preceptors talk about EOLC in a way that you suspected differed from how they actually practiced or from what they actually believed? Does your training on EOLC conflict with how you've learned you should be treating dying patients?

\section{EOLC Emotions}

Sometimes, caring for patients at the end of life can be very intense, emotional work.

What kinds of emotions come up for physicians around EOLC?

For medical students?

What have you been told officially or implicitly about the "right" way for physicians or medical students to handle these emotions (what you're supposed to do)?

\section{Explicit messages \\ Implicit messages \\ Response of others to physician emotions}

How has it been for you emotionally thus far? How will it be for you on the wards?

When you took care of a patient who died...

What was your reaction?

How did others respond to you about it?

\section{Personal Experiences}

Have you ever had an important person in your own life die?

Please describe the experience

Were you involved in their care? If so, how?

Has it affected your learning about EOLC?

\section{Conclusion}

Any other comments?

Thank you.

\section{References}

1. Cooke M, Irby DM, Sullivan W, Ludmerer KM (2006) American medical education 100 years after the Flexner report. N Engl J Med 355:1339-1344

2. Leach DC (2004) Professionalism: the formation of physicians. Am J Bioeth 4:11-12

3. Sullivan W (2005) Work and integrity: the crisis and promise of professionalism in America, 2nd edn. Jossey-Bass, San Francisco

4. Liaison Committee on Medical Education (2008) http://www. lcme.org/standard.htm. Accessed 27 May 2009.

5. Stern DT, Cohen JJ, Bruder A, Packer B, Sole A (2008) Teaching humanism. Perspect Biol Med 51:495-507

6. Fins JJ, Gentilesco BJ, Carver A et al (2003) Reflective practice and palliative care education: a clerkship responds to the informal and hidden curricula. Acad Med 78:307-312

7. Branch WT Jr, Kern D, Haidet P, Weissmann P, Gracey CF, Mitchell G, Inui $T$ (2001) The patient-physician relationship. Teaching the human dimensions of care in clinical settings. JAMA 286:1067-1074

8. Cruess RL, Cruess SR (1997) Teaching medicine as a profession in the service of healing. Acad Med 72:941-952

9. Sullivan AM, Lakoma MD, Block SD (2003) The status of medical education in end-of-life care: a national report. J Gen Intern Med 18(9):685-695

10. Hafferty FW, Franks R (1994) The hidden curriculum, ethics teaching, and the structure of medical education. Acad Med 69:861-871

11. Ratanawongsa N, Teherani A, Hauer KE (2005) Third-year medical students' experiences with dying patients during the internal medicine clerkship: a qualitative study of the informal curriculum. Acad Med 80(7):641-647

12. Feudtner C, Christakis DA, Christakis NA (1994) Do clinical clerks suffer ethical erosion? Students' perceptions of the ethical environment and personal development. Acad Med 69:670-679 
13. Rabow M, Gargani J, Cooke M (2007) Do as I say: curricular discordance in medical school end-of-life care education. J Palliat Med 10:759-769

14. Redinbaugh EM, Sullivan AM, Block SD, Gadmer NM, Lakoma M, Mitchell AM, Seltzer D, Wolford J, Arnold RM (2003) Doctors' emotional reactions to recent death of a patient: cross sectional study of hospital doctors. BMJ 327(7408): 185

15. MacQueen KM, McLellan E, Kay K, Milstein B (1998) Codebook development for team-based qualitative analysis. Cult Anthrop Methods 10:31-36

16. Ryan GW, Bernard HR (2003) Techniques to identify themes. Field Methods 15:85-109

17. Stern D (2003) The development of professional character in medical students. Hastings Center Report [serial online]. July
2000; 30(4):S26. Available from: MasterFILE Premier, Ipswich, MA. Accessed 21 Feb 2010.

18. Rabow MW, Remen RN, Parmelee DX, Inui TS (2010) Professional formation: extending medicine's lineage of service into the next century. Acad Med 85(2):310-317

19. Suchman AL, Williamson PR, Litzelman DK, Frankel RM, Mossbarger DL, Inui T (2004) Toward an informal curriculum that teaches professionalism: transforming the social environment of a medical school. J Gen Intern Med 19:501-504

20. Hafferty FW (1998) Beyond curriculum reform: confronting medicine's hidden curriculum. Acad Med 73:403-407

21. Sullivan AM, Warren AG, Lakoma MD, Liaw KR, Hwang D, Block SD (2004) End-of-life care in the curriculum: a national study of medical education deans. Acad Med 79(8):760-768 